\title{
¿Y mañana qué? Aproximaciones al presente desde la ciencia ficción latinoamericana del siglo XXI
}

\author{
BELISARIOZALAZAR Universidad Nacional de Córdoba - CONICET, Argentina / belazalazar@gmail.com
}

\section{Resumen}

El siguiente trabajo parte de una pregunta urgente: $¿ Y$ mañana qué?, es decir, ¿existe un mañana para nosotros los terrestres en este tercer planeta del sistema Solar? El calentamiento global y la desaparición de refugios que permiten el desarrollo de múltiples formas de vida, humanas y no humanas, así como de actores abióticos, ponen en duda la posibilidad de tener un futuro compartido aquí en la Tierra. En tiempos del Antropoceno, el biocapitalismo como sistema que gestiona y regula los modos de vida globalizados aniquila alternativas en el presente y destruye las condiciones materiales de sostenibilidad mínimas, la futurabilidad misma del presente. La crítica al humanismo antropocéntrico, que postula al humano como único existente dotado de agencia, se torna necesaria para poder pensar un mañana poshumano. A partir del análisis de dos novelas de ciencia ficción latinoamericanas editadas en este nuevo milenio - Las constelaciones oscuras (Oloixarac) y La segunda enciclopedia de Tlón (Meier) - pretendemos abordar estas cuestiones. Lo poshumano, que no es sino ese presente negado por el sueño del Capital, significa una herida mortal al humano moderno. Nuevos horizontes se abren en los cuales la inmanencia radical supone una redistribución de los agentes de la geohistoria.

\section{Palabras clave: ciencia ficción / agencia / \\ biocapitalismo / poshumano}

\section{For what tomorrow? Approximations to the present from the latinoamerican science fiction of the XXI century \\ Abstract}

The following work is based on an urgent question: What about tomorrow?, that is to say: Is there a future for us, for terrestrial beings in this third planet of our solar system? Global warming and the disappearance of refugia that allows the development of multiple liveforms, such as human, not human as well as abiotic actors, create doubts concerning the possibility of having a shared future in the Earth. During the Anthropocene era, biocapitalism as a system that manages and regulates global ways of life, destroys not only choices in the present but also the minimal conditions of material sustainability, the futurability itself of the present. Criticism of the anthropocetric humanism, which states humans as unique beings with agency, becomes necessary in order

Recibido: 1/3/2020. Aceptado: 20/4/2020

Para citar este artículo: Zalazar, B. (2020). ¿Y mañana qué? Aproximaciones al presente desde la ciencia ficción latinoamericana del siglo XXI. El taco en la brea, 11 (diciembre-mayo), 153-163. Santa Fe, Argentina: UNL. DOI: 10.14409/tb.vii11.9164 
to think in a posthuman future. From the analysis of the two Latin American science-fiction novels published in this new millennium, -Dark constellations (Oloixarac) and La segunda enciclopedia de Tlón (Meier) — we try to deal with these issues. The posthuman condition, which is a mere present refused by the Capital dream, means a deadly wound to the modern human. New outlooks open up whereby radical immanence means a redistribution of geohistory agents.

Key words: science fiction / agency / biocapitalism / posthuman

Hay que hacerse a la idea: jhemos entrado irreversiblemente en una era a la vez postnatural, posthumana y postepistemológica! ¿Son demasiados «post»? sí, pero es porque todo ha cambiado a nuestro alrededor. Ya no somos exactamente humanos modernos a la antigua, iya no vivimos en la época del Holoceno! Bruno Latour

\section{La pregunta}

¿Y mañana qué? La pregunta retoma el título de un libro que reúne la transcripción de conversaciones mantenidas entre Elizabeth Rudinesco y Jacques Derrida. La actualidad de la pregunta, el hacerla contemporánea de nuestro hoy, presente desfasado, que pugna por mantener su estatuto material, complejo, frente al tiempo vacío y homogéneo del Capital, puede ser formulada así: ¿Mañana, qué mañana? ¿Hay mañana para nosotros, aquí en la Tierra? ¿Quiénes podrían conformar ese «nosotros» en un posible mañana incierto, en el que la apertura al por-venir parece cada vez más angosta? El interrogante, la vacilación, es sobre la posibilidad, ya no solo de imaginar un «mundo otro», una alternativa al modo de vida desfuturizante (Escobar) del capitalismo en su fase bio-cognitiva, sino de sostener las condiciones de sostenibilidad mínimas para el despliegue sympoietico entre lo biótico y lo abiótico que definen el decurso particular de nuestro planeta Tierra.

\section{La trama apocalíptica del Antropoceno}

El género de ciencia ficción producido en territorio latinoamericano en lo que va del siglo XXI, se hace cargo de esta acuciante y urgente problemática. Intentaré llegar al puerto desde el cual dilucidar si determinadas narrativas de esa ciencia ficción pueden servir como cartografías móviles, de cuatro dimensiones, para pensar desde el presente, espacios con expectativas de futuros materialmente reales.

La urgencia de la pregunta con la que comenzamos deriva del hecho, la facticidad relevada por multiplicidad de discursos y disciplinas, del acelerado deterioro de los espacios vitales, los refugios dirán Anna Tsing y Donna Haraway, a partir de los cuales las diferentes especies pueden sobrevivir y reconstituirse en condiciones desfavorables o luego de eventos extremos como la desertización, la deforestación, etc. Pensando en los actores de este deterioro o destrucción de los refugios, no se trata ya, como podría esperarse si nos ubicamos en el gran tiempo de la geohistoria de la indefinida intracción ${ }^{2}$ de los terraformadores (bacterias, hongos, plantas, animales humanos y no-humanos y artefactos técnicos), sino de la inflexión antropogénica en tanto fuerza modular que matriza y cambia el juego de los actores bióticos y abióticos en el tercer planeta del sistema Solar. El cambio de escala en la incidencia de ántropos sobre el «destino» de la geohistoria marca un evento-límite, una frontera a partir de la cual los relatos del Apocalipsis se pliegan al presente 
de un modo viscoso, tal como lo hacen los hiperobjetos para Timothy Morton. Los Modernos, diseminados en todo el orbe, hemos tomado el suelo y dispuesto el territorio a través de los lentes epistémicos de un utilitarismo mercantil a ultranza. El homo oeconomicus objetiviza y objetifica su «mundo circundante» desanimando la materialidad del cosmos, incapaz de percibir (dejarse tocar por) la capacidad de actuar (agency) de los múltiples existentes con los que debería co-habitar/ co-existir.

En estas primeras décadas del siglo XXI, hemos adquirido una potestas annihilationis, a través de sistemas sociotécnicos complejos tales como las biotecnologías y el circuito recursivo digital como Big Data, supeditados a la lógica predatoria del capital financiero globalizado. La sexta extinción masiva acecha como el espectro inhumano, con rostro demasiado humano, los imaginarios tardomodernos, murmurando amenazante: «nada habrá existido» (Anders en Ludueña Romandini, 2017:41). Como escribimos junto a Marcelo Silva Cantoni: ¡Malvenidos al Antropoceno!, el espacio-tiempo signado por la destrucción de espacios y tiempos plurales que hicieron y hacen de refugios para otros sujetos (pos)humanos y otros seres (Haraway).

Esbozaré, aquí, ahora, pues, como hemos visto, desde hace un tiempo, siempre habremos de decir «aquí, ahora, en el presente de esta geohistoria»; esbozaré, digo, un análisis embrionario que permita, quizás, alterar la idea-fuerza del progreso sostenida por la filosofía de la historia plana (¿unidimensional?) del capital. Filosofía plana, humanista y antropocéntrica que no ha cesado de producir expulsiones brutales (Sassen) dejando tras de sí un cementerio de ruinas y cadáveres incontables. En los últimos cuarenta años, este proceso se ha acelerado, despojando a ingentes colectivos humanos que subsisten (y mueren) en la pobreza extrema de las redes de salud pública, de empleos y de sus hogares; así como a otras especies y grandes cantidades de biomasa y agentes abióticos de sus espacios vitales y/o de existencia.

\section{Sin futuro no hay arqueología: (Bio)capitalismo y ciencia ficción}

Como dice Jameson en Arqueologías del futuro. El deseo llamado utopía y otras aproximaciones de ciencia ficción:

no es sólo la invencible universalidad del capitalismo la que está en cuestión, deshaciendo incansablemente todos los avances sociales obtenidos desde el comienzo de los movimientos socialistas y comunistas, revocando todas las medidas de bienestar, la red de seguridad, el derecho de sindicación, las leyes reguladoras industriales y ecológicas, y ofreciendo privatizar las pensiones y de hecho desmantelar todo lo que se interponga en el camino del libre mercado en todo el mundo. Lo devastador no es la presencia de un enemigo sino la creencia universal no sólo de que esta tendencia es irreversible, sino de que las alternativas históricas al capitalismo se han demostrado inviables e imposibles, y que ningún otro sistema socioeconómico es concebible, y mucho menos disponible en la práctica. (8)

Las novelas Las constelaciones oscuras de la argentina Pola Oloixarac (2015), y La Segunda enciclopedia de Tlón (2007) del chileno Sergio Meier me servirán de transistores para leer un conjunto de narrativas que permiten abrir fisuras en, o bien ensanchar el plano de acción del humano moderno regido por la lógica mercantilista de explotación y acumulación infinita. Las narrativas poshumanas y transhumanistas se abren como variables en un espectro de posibles que amplían y cierran, respectivamente, la dimensión futura de la biosfera. 
¿Por qué elegir relatos literarios pertenecientes a un género cuya vocación estructural deposita sus estrategias narrativas en recrear mundos que transcurren en futuros, ya sean lejanos o próximos? ¿No estamos acaso diciendo que el futuro se erige como una cesura ontológica para las sociedades tecnológicamente dirigidas? El futuro parece ser más una ilusión propia de una élite del Norte Global que una probabilidad razonable en la era del Antropoceno.

Retomando las tesis de Fredric Jameson sobre la auténtica relación de la ciencia ficción con el futuro, podemos afirmar que:

\begin{abstract}
lo que de hecho hay de auténtico en él, como modo narrativo y como forma de conocimiento, no es en absoluto su capacidad para mantener el futuro vivo, ni siquiera en la imaginación. Por el contrario, su vocación más profunda es demostrar y dramatizar una y otra vez nuestra incapacidad para imaginar el futuro, para personificar por adelantado, mediante representaciones en apariencia completas que en una inspección más profunda demuestran estar estructural y constitutivamente empobrecidas, la atrofia en nuestro tiempo de lo que Marcuse ha llamado la imaginación utópica, la imaginación de la otredad y de la diferencia radical; alcanzar el éxito mediante el fracaso, y servir de vehículos inadvertidos e incluso involuntarios para una meditación que, partiendo hacia lo desconocido, se encuentra irrevocablemente plagada de lo completamente familiar y por lo tanto se ve inesperadamente transformada en una contemplación de nuestros propios límites absolutos. (...) y esto no debido a un fallo individual de la imaginación, sino como resultado del cierre sistémico, cultural e ideológico del que todos somos de un modo u otro prisioneros. (344-345)
\end{abstract}

Lo que la ciencia ficción nos devuelve, según el crítico estadounidense, por lo menos desde la segunda mitad del siglo XX, es nuestro presente como pasado de algo por venir. Arqueología del futuro minuciosamente elaborada mediante precisos movimientos de indirección y desfamiliarización o extrañamiento:

Es el momento presente -indisponible por derecho propio a nuestra contemplación, porque la enorme inmensidad cuantitativa de los objetos y de las vidas que comprende es inabarcable y por lo tanto inimaginable, y también porque está ocluido por la densidad de nuestras fantasías íntimas así como por la proliferación de estereotipos de una cultura de medios que penetra en cada zona remota de nuestra existencia- el que cuando volvemos de las construcciones imaginarias de la ciencia ficción se nos ofrece en forma de pasado remoto del mundo futuro, como si se tratara de algo póstumo y colectivamente recordado. (342)

Quisiera agregar algo crucial y específico de novelas como Las constelaciones oscuras y La Segunda Enciclopedia de Tlón, que expresan, en tanto síntomas, la singularidad de nuestra era, signada como piensa Braidotti, por la condición poshumana. Si es cierto que podemos pensar en estas novelas como vestigios que nos permiten trazar «los contornos de un movimiento narrativo más profundo y amplio en el que en cierta coyuntura histórica los grupos de una colectividad dada examinan con inquietud su destino, y lo exploran con esperanza o temor» (Jameson:337), entonces lo que se revela, al leer dichas novelas en clave poshumana, es que la «ambición demiúrgica de reducir la integralidad de los puntos de la Tierra a una base de datos universal y sin fondo» (Sadin:78) supone como corolario la aparición en escena de agentes no humanos con los cuales el sujeto encarnado humano, o desencarnado según la compleja trama holográfica de Tlón, ha de trabajar colaborativamente 
para mantenerse en el plano del Ser. Pues, la cesura a la que alude Jameson, tiene como una de sus causas la creencia materializada en estilos de pensamiento ${ }^{3}$ y técnicas de experimentación de altísima complejidad, cuyo lugar común es el lenguaje informacional como lenguaje de la naturaleza y de la vida. En palabras de Nikolas Rose: «el lenguaje informacional empleado para analizar la naturaleza, que surgiera en 1920, posibilitó la capitalización tecnológica de la vida (...) En cuanto tecnología controlada por el capital, se trata de un modo particular de apropiación de la naturaleza: literalmente, capitalizar la "vida"» (Rose:78).

Sin embargo, esto es algo que no podemos ver, de ahí la idea de síntoma a la que aludí hace instantes. La euforia consumista y la capitalización de la vida en sí propiciada por la bioeconomía (Rose), cuyas formas de vida suponen la mercantilización de todo lo vivo y lo no-vivo a través de tecnologías digitales y biogenéticas, imprimen sobre los individuos un ansia de futuro que volatiliza la experiencia material fundiéndola en un eterno presente que no pasa pero que paradójicamente cambia. Me explicaré: es lo que Jonathan Crary llama el empobrecimiento sensorial y la reducción de la percepción de lo otro de sí que culmina en un espacio-tiempo lineal y homogéneo marcado por la imperativa aparición de nuevos artefactos y productos técnicos. El empobrecimiento del campo de experiencia colectivamente recreada tiene como correlato la reducción aun mayor de los horizontes de expectativa propios del tiempo futuro. Lo que cambia, podríamos decir, es el decorado, pero la sensación es que todo eso que rodea al individuo (con sus pretendidamente fijos y reconocibles individual and personal boundaries) no forma parte de su mundo. El tiempo fluye en un acelerador de partículas donde no hay choques ni encuentros, el clinamen propio del materialismo aleatorio propuesto por el último Althusser deja de funcionar. El ansia que permea el espacio virtual de las redes sociales se viraliza en todo el cuerpo social, cuya vida cotidiana se ve «actuada y vivida» cada vez más por los agentes inteligentes robóticos digitales (celulares, i-pads, computadoras, aplicaciones, etc.).

Nos hemos quedado, en este siglo XXI, reducidos a mónadas sin historia, y por ende sin presente, incapaces de sentir y percibir los ritmos espesos del cosmos material. En unos minutos el fracking, o el modelo de plantación occidental uniforme acaban con bosques, hiperobjetos fósiles como el petróleo formados en siglos y milenios, o alteramos el equilibrio térmico del clima habitando, como resultado, en un Nuevo Régimen Climático (Latour) donde todo tiembla en la zona metamórfica que es Tierra.

\section{Constelaciones oscuras y enciclopedias cuánticas: la caída del humano y la emergencia de múltiples actores no-humanos}

Más allá de los argumentos de ambas novelas, lo que en ellas irrumpe, más acá o en la oscuridad más profunda y subterránea, en «zonas de la tierra que huyen del tacto humano» (Oloixarac:24), son actores no-humanos que la misma ceguera de la racionalidad cognitivo-económica, propia del Humanismo Moderno, había relegado al espacio inerte de los medios para el fin productivista de una vida plena abocada al confort individual y el beneficio antrópico. Humanismo que con el paso de los siglos fue reduciendo las temporalidades múltiples que in-sisten en el tráfico simbiótico de las diferentes especies ensambladas en ricos y caóticos, no exentas de violencias y abruptos finales, procesos eco-sistémicos.

En la novela de Sergio Meier, la tecnología explotada por las Doce Corporaciones y luego potenciada por un Isaac Newton dotado de un exoesqueleto (Hawking es el referente ausente) en el 
multiverso fractal lleno de Universos Virtuales Paralelos que configuran la Realidad de Tlón, por un lado; y las fuerzas silenciosas, microscópicas, que cosen con el hilo invisible de la información genética, la trama apocalíptica del Antropoceno en los tres siglos que recorren la trama de Las constelaciones oscuras, por otro, retiran al humano del centro exógeno en el que se posicionó desde por lo menos el siglo XVI. Ambas estrategias, sin embargo, son distintas y contrarias.

En el futuro intergaláctico de Tlón, el descentramiento en realidad significa la desaparición del hombre encarnado, sustituido en la Realidad dominada por la Matriz primero, y luego en la Realidad material habitada por Newton y Leibniz entre otros, por una instancia transhumanista en el que la conciencia se libera de sus ataduras orgánicas, supeditadas a las leyes entrópicas de la materia, para confundirse con la supuesta sustancia inmaterial que organiza todo lo existente. ${ }^{4}$ Se trata de un universo en el cual el humano no ha perdido su centro, sino que ha llegado al punto de poder crear él mismo, a través de la tecnología, las condiciones que rigen todo lo existente. En este multiverso neognóstico, los arcanos cósmicos han sido develados por la razón humana, la cual ha logrado manipular a su antojo esas mismas leyes. Es el imperio de la Mente Cuántica. El gobierno del ántropos crea y destruye realidades y mundos cual el niño nietzscheano, sin culpa. Se ha arribado al tiempo de la cosmopolítica transhumanista.

En este futuro steampunk, ${ }^{5}$ la Tierra ha desaparecido. La civilización humana viaja por el espacio intergaláctico, el cual se ha revelado como un sinfín de burbujas-universos conectadas por Umbrales secretos. El multiverso no es sino un conjunto superpuesto de membranas, cada una de las cuales posee sus leyes y $x$ dimensiones propias. La materia, producida por una Biomatriz cumple funciones holográficas, creando la «Realidad Original», la cual a su vez, a través de la taumaturgia tecnológica desarrollada por los hombres, encierra mundos artificiales unos dentro de otros. El objetivo de mentes como la de Newton o Leibniz, siguiendo las enseñanzas del Maestro, es trazar el mapa que lleve a la salida de esas realidades artificiales, y poder escapar incluso a las leyes contingentes de la materia orgánica. El deseo que habita esos intentos es el de la transmutación (cuántica, alquímica, mística) del cosmos a la medida de la mente humana. Conocer significa poder llegar a controlar, manipular y administrar lo real, saltar por encima de leyes como la entropía que se consideran fundamentales.

Si la Realidad puede ser reducida a una serie de fluctuaciones cuánticas, capaces de ser descubiertas y rediseñadas por los hombres, herederos de los Secretos de la biomatriz, lo que en este trabajo llamé agentes no-humanos o colaboradores sympoieticos, pierden ese estatuto, se disuelve su entidad ontológica separada del homo sapiens. Pasan a ser creaciones, contingencias menores. Con relación a esto, no parece ser dato aleatorio el que en esas Realidades hologramáticas de Tlón, animales y plantas, por ejemplo, no existan. Solo Leibniz logra recrearlas a partir de rudimentarios y anacrónicos artefactos técnicos, pero no cumplen más que un papel decorativo; son, a lo sumo, objeto de contemplación.

En tanto el Todo, la «Gran Obra» es nombrada en el multiverso ficcional de Meier, puede ser cambiado y creado por la mente humana, no existe nada que no pueda ser destruido por ella. ${ }^{6} \mathrm{El}$ Apocalipsis inducido por la sed de conocimiento sucede, de hecho:

Y he aquí que la primera luz fue encendida. En el vacío se formó un punto imperceptible, un «pensamiento», el estado primero de materia informe, sin dimensiones ni cantidad. La «Luz suprema».

El huevo cósmico se abrió. 
De la madeja del caos cuántico, los ingenieros semidioses comenzaron a desplegar los hilos, cual medusas de luz, tejiendo aquella forma de geometría perfecta. La nueva Jerusalén había sido descrita como «un cristal de antimonio rojizo y transparente, como una piedra preciosa» según Weigel, como «hecha de suavísimo cristal de oro» según Von Welling, o como «una novia ataviada para su marido» por Juan. Y consecuentemente los Alquimistas iban construyendo el tapiz de un más armonioso mundo material... (Meier:219).

En Las constelaciones oscuras sucede, a pesar suyo, es decir, a pesar del final en el que el capitalismo sigue intacto, un descentramiento de lo humano. El tráfico de las especies que rigen las coagulaciones contingentes de formas de vida terrestres desde la azarosa aparición de nuestro planeta, irrumpen desde la selva amazónica, en los tres grandes momentos $(1882,1983,2024)$ en que se divide el libro. Las fuerzas in-humanas subterráneas, así como los actantes provocados por las ciencias informáticas digitales y la biogenética, y luego su simbiosis expandida, operan la caída del centro y su posterior aniquilación. Los híbridos, que podemos pensar como los ensamblajes ricos en especies de los que hablan Haraway y Latour ingresan de lleno en el juego político de la supervivencia en la Terra.

Los agentes no-humanos emergen desde zonas inexploradas, vistas solo por sujetos como el enigmático naturalista Niklas Bruun; otros tantos son creados artificialmente, mezclándose con aquellos en una orgía que no es sino la historia natural de la Tierra. Esta orgía, la hibridación de los agentes, da cuenta de los procesos que trabajan más allá del control al que el biocapitalismo digital intenta subsumir la multiplicidad de temporalidades y existencias que insisten, aún hoy, en la Tierra del Antropoceno. La molecularización ${ }^{7}$ como estilo de pensamiento prevé, como de hecho lo hace Cassio en la novela de Oloixarac, que el código del fenómeno vida puede no solo ser conocido, sino controlado y manipulado: «procesos informacionales en tejidos vivos» (127). Cassio, por ejemplo, lo vislumbra a través de la invasión algorítmica de bots encriptados fabricados en laboratorios.

Estos agentes, fuerzas que actúan en las profundidades, zonas secretas que escapan al tacto humano, ya están trabajando y colaborando desde antes de que sean descubiertas por las ciencias humanas. Estromatolitos, cangrejos albinos, orquídeas como la Crissia pallida, insectos, gusanos, virus, bacterias, ratas, etc. trafican información a lo largo de la historia, conformando la caótica trama de la simbiosis planetaria. A ellos se suman ahora nuevos seres biológicos y digitales creados artificialmente por el conocimiento y la ingeniería tecnológica. Pareciera que «todo está abierto para ser franqueado y permeado» (Oloixarac:67). La mente predatoria de Cassio, symbolon de lo que pensadores como Sassen llaman las formaciones predatorias de nuestro tiempo, interpreta esta apertura como una posibilidad para reconstruirlo todo desde el pequeño espacio del vertebrado humano. El cálculo al servicio de la optimización de una especie como la del homo sapiens (si es que tal cosa existe en nuestros días) cancela el tiempo, y su visión antropogénica del decurso terrestre busca anular o desconocer la "ciudadanía» y la agencia de esos otros, que, a pesar suyo, han comenzado a hacerse sentir con más fuerza a través de efectos como el calentamiento global. No obstante, la simbiosis continuará, y lo hará aun en nuestra ausencia.

La selva amazónica primero, y la Patagonia argentina, centurias más tarde, se revelan como el continente del Antropoceno en Las constelaciones oscuras; el lugar donde «la hermandad entre los seres [se da] en formas que jamás hubiésemos podido imaginar (Oloixarac:137-138). El viaje 
que proponen Niklas Bruun, Tartare d'Hunval y luego Cassio, Piera y los científicos reunidos en el proyecto Estromatoliton, es un recorrido por incontables eras geológicas, alucinado, onírico, dibujado con pinceles teñidos de horror y esperanza. En el ambiente epigenético la única ley real radica en que todas las acciones, de cualquier agente que se trate, tienen un efecto en el espacio. Esas acciones caen en un estanque primordial y sus efectos perduran en el tiempo, mezclándose unas con otras, sin poder reconocer a ciencia cierta dónde comienza una y dónde termina otra.

Cada vez sabemos más de las cosas, las manipulamos mejor — dijo Max (...)— Y cada vez nos son más extrañas. Se alejan. (...) Hay que verlas como las constelaciones oscuras, como llamaban los incas a su sistema de cielos, que definían en términos de los intervalos de oscuridad entre las estrellas, las formas interiores de unos perímetros brillantes. Lo que arma el espacio significativo no es el contorno, no son los puntos brillantes, no es la presencia de luz, la luz es el ruido en las constelaciones oscuras. Los que significan son los espacios negros entre los puntos. Cada vez sabemos más, tenemos más información, pero desde el punto de vista de las constelaciones oscuras, desde el fondo perdemos de vista el contorno. (Oloixarac:194-195)

\section{El humanismo, otra vez}

Hice referencia al Humanismo, y postulé que precisamente es la figura de lo humano que se desprende de ese gran dispositivo occidental, la que habilita el cuestionamiento sobre su supervivencia, fortalecimiento o desaparición, cuestión clave para pensar sobre el ¿mañana, qué mañana?, que abrió estas reflexiones.

¿De qué tipo de humano estamos hablando? Se trata del ideal del Hombre delineado por las doctrinas del humanismo occidental desperdigado en una serie de valores intelectuales, discursivos y espirituales y elevado a contexto normativo, proyecto civilizacional y práctica institucionalizada a lo largo de la Modernidad (Braidotti). Esa imagen interpreta a lo humano en términos puramente cognitivos devolviendo una narrativa histórica en términos de perfectibilidad y «potenciación de las capacidades humanas biológicas, racionales y morales a la luz del concepto de progreso racional orientado teleológicamente» (Braidotti:25). El último avatar de esa imagen es el homo oeconomicus al que hicimos referencia anteriormente. En el espacio-tiempo reducido del capitalismo contemporáneo,

cuando habría que tener tantas definiciones de la humanidad como pertenencias al mundo existen, ${ }^{8}$ es el momento mismo en que se ha logrado universalizar por fin sobre la superficie de la Tierra el mismo humanoide economizador y calculador. (...) jJusto en el momento en que tenemos una cruel necesidad de otras formas de homodiversidad! (...) hay que enfrentar el mundo con un humano reducido a un pequeñísimo número de competencias intelectuales, dotado de un cerebro capaz de hacer simples cálculos de capitalización y de consumo, al que se atribuye una pequeña cantidad de deseos y al que se ha logrado convencer por fin de tomarse realmente por un individuo, en el sentido atómico de la palabra. (Latour:127)

Paradójicamente, en este marco reduccionista, los actores capaces de responder a la violencia del capital hacen su entrada en escena, reconfigurando la cartografía material y volviendo a poner la historia en marcha, saltando por fuera de la poshistoria a lo Fukuyama, para sumergirnos de lleno en la geohistoria. Como dice Zizek, existen problemas en el Paraíso, y necesitamos potenciar 
las capacidades para hacer un claro diagnóstico con el cual pronosticar una salida de todo esto. El Apocalipsis now al que refieren pensadores como Latour y Ludueña Romandini, retomando las alarmas de Gunther Anders y Karl Jaspers, nos devuelve a la co-responsabilidad ética y política de los terrestres para reconstruir los refugios, para imaginar $\mathrm{y}$ «volver a gozar cada día la oportunidad de estar aquí, ridículos pero siempre de pie (Anders en Latour:244). El retorno de lo reprimido por el reduccionismo hace temblar a los Modernos sobre lo que son y el suelo en el que viven, obligándonos, y devolviéndonos por fin, el presente perdido.

La condición poshumana, que no es sino ese presente negado por el sueño del Capital, significa una herida mortal al humano moderno. Nuevos horizontes se abren en los cuales la inmanencia radical supone una redistribución de los agentes de la geohistoria. Y por si esto fuera poco, la cosmología pos-einsteniana nos ubica en un universo infinito. Cada «individuo» no es sino un punto numérico dispensable, un grano de polvo, un momento en las aventuras de las vibraciones cósmicas. Un universo an-antrópico implosiona el Mito Humanista desde dentro. Necesitamos alimentar esos futuros, algunos de los cuales ya existen hoy, pero se hallan invisibilizados por la ratio occidental capitalista, ya sea exiliándolos al terreno de las no-existencias (ausencias) o aniquilándolos en su larga marcha por la conquista y la producción del Globo.

Me gustaría cerrar este trabajo, un cúmulo de problemáticas cuyo horizonte es ese deseable y escurridizo mañana, con una cita de Fabián Ludueña Romandini:

En lugar de lamentarse, hay que asumir con radicalidad la nueva situación. En ella podrá quizá aparecer lo que algunos llaman, en un acto de valentía que ya veremos si pueda transformarse en una facticidad plausible, una singularidad. Sin embargo, para que esto sea posible, habrá que asumir la apuesta del universo infinito y la subjetividad que éste propone. Que el hombre no sea más que un punto matemático supone, sin lugar a duda, el final del Humanismo tal y como, en diversas formas, fue concebido, por lo menos, hasta los Tiempos Modernos. (2016:216)

\section{Notas}

1 El concepto de geohistoria intenta superar la división entre historia natural e historia humana establecida por la partición disciplinar de los saberes a lo largo de los siglos XIX y XX. Si bien el concepto fue ideado por Fernand Braudel, seguimos los lineamientos de Bruno Latour, quien a su vez retoma, entre otros, las ideas esbozadas por Chakrabarty en un artículo, aparecido en 2009, titulado "Clima e historia: cuatro tesis». Desde esta perspectiva, es posible estudiar los distintos sucesos y procesos que han ido con-formando la historia de la Tierra. Esto implica tomar a la especie homínida (categoría en sí misma puesta en cuestión) como uno de los tantos agentes, entre otros existentes/actores, y no ya como un ser excepcional, racional, único dotado de agencia y por ello habilitado para administrar la materia en pos de la mejora de su propio mundo sociocultural autocentrado. Incluso podemos extender la geohistoria para encadenarla a la Gran Historia del cosmos. La era del Antropoceno dentro de esa geohistoria, se caracteriza por el ascenso de los seres humanos y su forma de vida capitalista al estatus de fuerza geológica capaz de modificar abruptamente el equilibrio térmico de la zona habitada por los variados colectivos terrestres.

2 El término intracción proviene de la propuesta ontológica (realismo agencial) introducida por Karen Barad en Meeting the universo Halfway. La intracción supone que no hay agentes o elementos agentes que entran en relación y se transforman a partir de esa interacción, sino que los existentes (gentes terrestres en todas sus formas) emergen de relaciones y encuentros intractivos, no preexisten a sus configuraciones entrelazadas de 
mundos. En la intracción desaparecen conceptos y categorías como las de individuo, ambiente, entornos, etc.

3 Nikolas Rose, siguiendo a Ludwik Fleck, define un estilo de pensamiento de este modo: «Un estilo de pensamiento es un modo particular de pensar, ver y ejercer. Supone formular enunciados que solo son posibles e inteligibles en el marco de un modo de pensar. (...) Un estilo de pensamiento también supone ser miembro de una "comunidad de pensamiento" en el marco de una disciplina o subdisciplinas así como un conocimiento íntimo de las relaciones de poder y estatus de ese colectivo. (...) Un estilo de pensamiento no solo configura cierta forma de explicación, en qué consiste explicar, sino también qué hay para explicar: define y establece el objeto de explicación, el conjunto de problemas, temas, fenómenos de los que la explicación procura dar cuenta. (...) Un estilo de pensamiento no es meramente un discurso [implica asimismo una serie de] técnicas de experimentación de altísima complejidad». (40-41).

4 Paula Sibilia, y sobre todo el primer tomo de La comunidad de los espectros de Ludueña Romandini (2010) suponen un aporte ineludible sobre los lineamientos del transhumanismo.

5 El stempunk, en literatura, es un subgénero de ciencia ficción que se desenvuelve en un futuro, a veces ucrónico, en el cual tecnologías de siglos pasados, en especial la maquinaria de la primera Revolución Industrial, así como personajes históricos, sobre todo del campo de la ciencia moderna, conviven con elementos e invenciones futuristas inspiradas en el conocimiento de las ciencias y la tecnología contemporáneas al autor de las obras.

6 La idea, narrativizada en el Apocalipsis desencadenado por la batalla entre Newton y Leibniz, recuerda al final del clásico cinematográfico Akira, perteneciente al anime cyberpunk.

7 La molecularización refiere a un estilo de pensamiento propio de la biomedicina y de la biología contemporánea, según la cual la vida en todos sus niveles está regida por el lenguaje codificado de los genes. La genómica molecular parte de la idea de que «tejidos, células y fragmentos de ADN pueden hacerse visibles, aislarse, descomponerse (...) reestructurarse mediante manipulación molecular: es posible transformar sus propiedades, suprimir o eliminar sus vínculos con un organismo, tipo o especie viva particular» (Rose:45).

8 Tiempos en que debemos aprender a convivir con hiperobjetos como el calentamiento global, el uranio, el mercurio y el plutonio, los agrotóxicos como el glifosato, y las 400 zonas muertas en los océanos del mundo como efecto de la hiponia y la suba del nivel de ácido en los acuíferos terrestres.

\section{Referencias bibliográficas}

Braidotti, R. (2015). Lo poshumano. Barcelona: Gedisa.

Haraway, D. (2016). Antropoceno, Capitaloceno, Plantacionoceno, Chthuluceno: generando relaciones de parentesco. Revista Latinoamericana de Estudios Críticos Animales, I, Año III, 15-26. http://revistaleca.org/ journal/index.php/RLECA/article/view/53

Escobar, A. (2017). Autonomía y diseño. La realización de lo comunal. Buenos Aires: Tinta y limón.

Jameson, F. (2009). Arqueologías del futuro. El deseo llamado utopía y otras aproximaciones de ciencia ficción. Madrid: Akal.

Latour, B. (2017). Cara a cara con el planeta. Una nueva mirada al cambio climático alejada de las posiciones apocalípticas. Buenos Aires: Siglo XXI.

Ludueña Romandini, F. (2010). La comunidad de los espectros I. Antropotecnia. Buenos Aires: Miño y Dávila. (2016). La comunidad de los espectros II. Principios de espectrología. Buenos Aires: Miño y Dávila. (2017). El nacimiento de la catástrofe. Una aproximación histórico-metafísica. En Acerbi, J.;

Borisonik, H. y Ludueña, F. (Comps.). Viviendo la catástrofe. Inseguridad, capitalismo y política. Tierra del Fuego: UNTDF, 25-50.

Meier, S. (2007). La segunda enciclopedia de Tlón. Valparaíso: Puerto de escape.

Morton, T. (2018). Hiperobjetos. Filosofía y ecología después del fin del mundo. Buenos Aires: Adriana Hidalgo.

Oloixarac, P. (2015). Las constelaciones oscuras. Buenos Aires: Random House Mondadori. 
Rose, N. (2012). Políticas de la vida. Biomedicina, poder y subjetividad en el siglo XXI. La Plata: UNIPE, Editorial Universitaria.

Sadin, E. (2017). La humanidad aumentada. La administración digital del mundo. Buenos Aires: Caja Negra.

Sassen, S. (2015). Expulsiones. Brutalidad y complejidad en la economía global. Buenos Aires: Katz editores.

Sibilia, P. (2010). El hombre postorgánico. Cuerpo, subjetividad y tecnologías digitales. Buenos Aires: Fondo de Cultura Económica.

Silva Cantoni, M. y Zalazar, B. (2018). Humanos, malvenidos al Antropoceno. Terrestres en pie de guerra. Revista Heterotopías del Área de Estudios del Discurso de FFyH, 1(1). https://revistas.unc.edu.ar/index.php/ heterotopias/article/view/19991/23162 